Federal Reserve Bank of Minneapolis

Research Department Staff Report 236/JV

\title{
Monopoly Rights: A Barrier to Riches*
}

\author{
Stephen L. Parente \\ University of Pennsylvania \\ Edward C. Prescott \\ Federal Reserve Bank of Minneapolis \\ and University of Minnesota
}

\begin{abstract}
Our thesis is that poor countries are poor because they employ arrangements for which the equilibrium outcomes are characterized by inferior technologies being used, and being used inefficiently. In this paper, we analyze the consequences of one such arrangement. In each industry, the arrangement enables a coalition of factor suppliers to be the monopoly seller of its input services to all firms using a particular production process. We find that eliminating this monopoly arrangement could well increase output by roughly a factor of 3 without any increase in inputs.

*The views expressed herein are those of the authors and not necessarily those of the Federal Reserve Bank of Minneapolis or the Federal Reserve System.
\end{abstract}




\title{
Monopoly Rights: A Barrier to Riches
}

\author{
By Stephen L. Parente and Edward C. Prescott*
}

\begin{abstract}
Our thesis is that poor countries are poor because they employ arrangements for which the equilibrium outcomes are characterized by inferior technologies being used, and being used inefficiently. In this paper, we analyze the consequences of one such arrangement. In each industry, the arrangement enables a coalition of factor suppliers to be the monopoly seller of its input services to all firms using a particular production process. We find that eliminating this monopoly arrangement could well increase output by roughly a factor of 3 without any increase in inputs. (JEL D58, $\mathrm{O} 11, \mathrm{O} 41)$
\end{abstract}

Our view is that technology is the lever to riches and that all countries would be rich if they just applied this lever. Why don't poor countries use the better technologies that are available and become rich? We think that for many poor countries the answer is that they have protected monopoly rights. Our thesis is that absent these monopoly rights, a country will be rich. Individuals or groups of individuals will accumulate any human and physical capital needed to operate the better technologies. This, of course, assumes a market economy with well-defined property rights and taxes that are not confiscatory.

The monopoly rights we consider allow a group in each industry to be the sole supplier of its labor services to all firms using a particular production process. The coalition has the 
right to dictate work practices and its members' wages. These monopoly rights are protected via regulation that makes it costly for a group of potential adopters to enter the industry with a superior technology. The stronger is this protection, the greater the amount of resources a group of potential adopters of a superior technology must spend to overcome resistance to the use of that technology.

The effect of this arrangement on a country's output can be large. In the model restricted to be consistent with a number of observations between rich and poor countries, we find that eliminating monopoly rights increases gross domestic product by roughly a factor of 3 without any increase in inputs. This occurs even if the strength of the protection is modest. This analysis suggests that monopoly rights of the type we consider may be an important barrier to riches.

The view that monopoly power impedes economic progress and leads to economic inefficiencies is not new. This view dates back at least to Adam Smith (1937 pp. 712-13), who believed that monopoly provided protection for groups from "the superior vigilance and attention of private adventurers" and that in the long run, monopoly served only "to support the negligence, profusion, and malversation" of the group with the monopoly power. Alfred Marshall had a similar view. He saw free enterprise and not monopoly as the engine of economic efficiency and progress.

Despite strong empirical support, this classical view commands little respect in the economics profession today. The reason for this lack of respect is the lack of a plausible theoretical mechanism by which monopoly impedes economic progress and leads to large 
inefficiencies. There are, of course, some theoretical mechanisms by which monopoly leads to inefficiencies. One mechanism is the consequence of monopoly power creating a gap between marginal rates of substitution and transformation as modeled by Arnold C. Harberger (1954). Another mechanism is the consequence of capitalized monopoly rents on the accumulation of physical capital as modeled by John Laitner (1982). Both, however, generate inefficiencies which are at most a few percent of GNP. ${ }^{1}$ Unlike the Harberger-type analysis and the Laitner dynamic-type analysis, the cost of the monopoly rights considered here can be large. In this paper, therefore, we provide some much needed theoretical underpinnings for the classical view that monopoly impedes economic progress and leads to large inefficiencies.

Our view is in sharp contrast to the Schumpeterian view that monopoly fosters economic progress. According to Schumpeter, innovations require large nonfirm-specific investments, and monopoly profits are needed to finance these investments. This view is captured in the newly developed endogenous growth theory of Paul Romer (1990), Gene M. Grossman and Helpman (1991), and Philippe Aghion and Howitt (1992). We, however, doubt that poor countries are poor because they failed to foster enough monopoly power. We think that firms in poor countries can adopt the better technologies which are developed elsewhere in the world without having to make any large nonfirm-specific investments. The adoption of these better technologies may require large firm-specific and factor-specific investments, but such investments do not require monopoly rents to induce individuals to undertake them. For this reason, we do not find the factor emphasized by Schumpeter as being important in understanding why some countries are only one-twentieth as rich as some others. 
In our model, the mechanism by which monopoly rights impede economic progress is strategic. In each industry, there is a game between the coalition of factor suppliers which has the monopoly rights over the current production process and a potential entrant. If there is entry, the entrant uses a superior technology. Any firm in the industry that uses the existing technology must employ coalition members to operate the technology, must pay a wage that is set by the coalition of factor suppliers, and must follow the work practices specified by the coalition. Additionally, the coalition has the right to set its membership size. Since the rights of a coalition are protected, a group of potential adopters must first overcome resistance before it can use the superior technology.

The return to entry depends on both the strength of protection and the number of coalition members. Membership size acts as a deterrent to entry. When protection is weak, entry occurs since the coalition size that would deter entry would also imply an inadequate compensation to retain and attract members. With stronger protection, entry does not occur and, if protection is not too strong, coalition membership is above the number of members needed to produce the equilibrium output. Thus, there can be both an inefficient use of an inferior technology and a failure to adopt the better technology under the monopoly rights arrangement that we consider.

Our work in this paper relates to the industrial organization literature, which uses capacity as a strategic deterrent to entry. For example, see Finn E. Kydland $(1973,1979)$, Michael Spence (1977), Richard Schmalensee (1978, 1981), Avinash Dixit (1979, 1980), and Beth Allen et al. (1995). All of their models, unlike ours, are partial equilibrium models. 
Additionally, with the exception of Allen et al.'s, these models employ Cournot post-entry competition and have the property that the outcome of the subgame perfect equilibrium is not characterized by excess capacity. Like the model of Allen et al., our model employs Bertrand-Edgeworth competition and has the property that the outcome of the subgame perfect equilibrium is characterized by excess capacity.

Our model shares many of the features and themes of the development models of Romer (1994), Kevin M. Murphy et. al (1989a, 1989b). Like these authors, we use the differentiated commodities structure of Spence (1976) and Avinash K. Dixit and Stiglitz (1977). However, we have constant returns to scale technologies with no fixed costs. An implication of this is that there is no need to have monopoly rents to finance the cost of introducing better technologies. Like Murphy et al. (1989a), we have a fixed commodity space and like Murphy et al. (1989b), we have an agriculture sector as well as an industrial sector. There are rents in our model. However, unlike the models of Anne O. Krueger (1974) and Jagdish N. Bhagwhati (1982) no resources are wasted in the process of individuals seeking these rents.

We organize this paper as follows. Section I reviews some empirical evidence that such monopoly rights arrangements exist and have resulted in both the nonadoption of superior production technologies and the inefficient operation of current technologies. Section II describes the economy. Section III defines equilibria with monopoly rights. Section IV describes how to compute the equilibria. Section V reports some quantitative findings of the theory. Section VI examines whether coalition members can be compensated by a group 
that adopts the superior technology in a way which makes adopters and coalition members better off. The final section contains a brief summary and some concluding remarks.

\section{Some Empirical Evidence}

The key element of our abstraction is that groups of factor suppliers have monopoly rights that are tied to currently used production processes and that such rights have value. The industrial organization is not a key element. In our model, industries are competitive and private; however, they need not be. Our theory applies equally to the case in which industries are public or private monopolies. In this section, we present evidence that monopoly rights of the type we consider are important to prevent the use of better work practices and are more prevalent in poor countries than in rich countries.

How widespread these monopoly rights are in a country depends largely on the behavior of the state. Through a variety of methods, the state can protect a group of factor suppliers by prohibiting firms in the industry from implementing changes in work practices that would increase productivity and reduce employment. The state can outright prohibit reductions in employment by writing laws to this effect. In India, for example, firms with more than 100 workers must obtain the government's permission to terminate any worker, and firms of all sizes are subject to state certification of changes in the tasks associated with a job. Large severance payments to laid-off workers are another way in which the state pro-

tects these monopoly rights. A less direct but effective method involves the state sanction of violence and strikes. In those instances in which a change in work practices requires the use 
of imported machines, the state can effectively prevent the implementation of these changes by denying the firm a license to import the needed machines.

Recent attempts by several countries to privatize state-owned enterprises reveal the extent of the protection the state in poor countries has afforded specific groups of factor suppliers. In Bangladesh, for example, private buyers of the once national jute mills were prohibited for one year from laying off any of the workforce they inherited. After one year, a worker could be laid off but not without a large severance payment. According to Klaus Lorch (1988), this payment was between three and five months' wages plus an additional month's wages for every year the worker had been with the firm. In Malaysia, the guidelines for privatization prohibited new owners from reducing their workforce for a total of five years. In Central America, these rights are strongly protected as well. According to Laing Gray Cowan (1990), a worker's rights in state-owned enterprises in Panama are so strongly protected that any private buyer can expect to make severance payments equal to two or three times the worker's annual wages.

These actions to prohibit firms in an industry from changing work practices are irrelevant unless the state also protects the industry from outside competition. In effect, the monopoly rights of the group of factor suppliers are valueless unless entry by foreign and domestic firms and expansion by existing firms are made prohibitively costly. To prevent entry by foreign firms, the state can impose high tariff rates and stringent quotas. The poorest countries in the world are notorious for having the most restrictive trade policies. In these countries, the state limits entry by domestic firms and expansion by existing firms 
in the industry primarily by regulation. In India, this is achieved by requiring licenses to enter and licenses to expand production. Also in India, regulations require certain firms to award workers with lifetime employment and require firms with more than 25 workers to use official labor exchanges to fill any vacancy. The state can and often does discourage entry by firms that use more productive work practices through the subsidization of existing firms.

In many of the rich industrialized countries, the state typically grants workers the right to unionize and, in some countries, requires unionization. The state, however, typically does not protect producers in these industries from outside competition. This is an important distinction between the rich and the poor countries. In rich countries, while unions have some ability to block firms that employ them from adopting better work practices, these unions typically do not do so. If a union blocked better work practices, that would end the union's industry in its country. Canada, for example, is one of the richest countries in the world and has many unionized industries. Still, this has not inhibited efficient production there because Canadian firms are not protected from U.S. competition.

A case in point that shows how the level of state protection of these monopoly rights determines the extent to which work practices change and productivity increases is the Indian and Japanese textile industry between 1920 and 1938. Over this period, output per worker increased by 120 percent in Japan and 40 percent in India. According to Susan Wolcott (1994), these increases were not associated with purchases of more or better equipment, but rather were accomplished by work practice changes that effectively increased the number of machines operated per worker. Productivity grew more slowly in India as work practices 
changed less there. According to Wolcott (1994) these differences in productivity growth reflect differences in labor's ability to resist employers' attempts to increase the number of machines each worker operated.

Because of the inelastic demand for textiles, workers associated the loss of jobs with the implementation of these work practices. The mechanism by which Indian textile workers attempted to block the introduction of better work practices was strikes. In the interwar period, roughly 1,000 such strikes occurred. Strikes in India would have been far less successful, and thus probably less frequent were it not for the protection the state afforded to textile workers. When the inefficient Indian textile industry was threatened by foreign competition, the Indian government reacted by increasing the tariff rate on imported textiles. In contrast, Japanese textile workers received little protection from the state. Strikes in Japan, in fact, were rare. The one major strike in the textile industry that did occur was quickly put down, and the majority of participants were replaced.

Indian textile workers had the state's protection, and thus the greater ability to prevent changes in work practices from being implemented, because they had the greater incentive to secure monopoly rights and the state protected these rights. Wolcott's (1994) thesis is that Indian workers had the greater incentive to prevent changes in work practices from being implemented because textile workers in India were adult males who expected to spend their entire lifetimes working in the mills. In Japan, in contrast, workers were typically illiterate girls from the provinces, who generally worked in the mills only a few years before getting married. 
The textile industry provides strong evidences that productivity can vary substantially as a result of differences in work practices. Gregory Clark (1987) documents that in 1910, labor productivity in the cotton textile mills differed by a factor of 7 across countries and that these productivity differences were the result of differences in work practices. Workers in the less productive countries such as India and Japan operated far fewer looms than workers in the more productive countries such as the United States and Great Britain. Clark finds that these differences in work practices cannot be explained by differences in education, nutrition, or factor prices.

Clark (1987) documents that attempts by employers to increase the number of looms operated per worker created conflicts with workers in almost all but the most productive regions. In India, the conflict was over two years versus one loom per weaver; in Russia, three versus two looms per weaver; in France and Mexico, four versus three looms per weaver; in Great Britain, six versus four looms were weaver. The resistance by workers is evidence that constraints on work practices mattered for productivity. This leads to the question of why the results of these conflicts varied across countries. Clark (1987) offers culture as an explanation. We disagree. Instead, our candidate for an explanation is differences across countries in the incentives and abilities of workers and existing firms to dictate industry work practices. The ability to dictate industry work practices differs in large part because of the different behavior of the states.

Recently, some poor countries have attempted to assure potential investors that monopoly rights of factor suppliers will not be protected so strongly in the future. Some of 
this assurance has been written into investment codes that promise that the state will not interfere with the operation of private firms. The Guinean code of 1987 - which according to Keith Marsden and Belot (1987), is similar to Madagascar's revisions and many other subSaharan countries' codes - guarantees that private-sector firms be able to import necessary raw materials and equipment and export production, set and implement their own employment policy, determine their customers and input suppliers, repatriate earnings, and be free of unfair competition from parastatal firms. That countries felt compelled to write such codes is evidence that firms were restricted by the state in setting their employment policies and determining their own suppliers. Whether the promises in these codes are credible is another issue.

\section{The Economy}

In this section, we describe the basic structure of the economy. The economy consists of a household sector, an industrial sector, and a farm sector. Industrial sector goods can be produced with one of three technologies, each with different labor input requirements per unit of output. In any period, a household is one of three things: a worker in the farm sector, a worker in the industrial sector, or part of a group of entrepreneurs who adopt a technology in the industrial sector. 


\section{A. Household Sector}

The household sector contains an atomless measure $N$ of infinitely lived households, each with utility defined over an agricultural good $a(t)$ indexed by date $t \in\{0,1,2, \ldots\}$ and differentiated goods $x(i, t)$ indexed by type $i \in[0,1]$ and by date $t \in\{0,1,2, \ldots\}$. The utility function is

$$
\sum_{t=0}^{\infty} \beta^{t}\left[\left[\int_{0}^{1} x(i, t)^{\gamma} d i+\mu a(t)^{\gamma}\right]^{\theta / \gamma}-1\right] / \theta,
$$

where $0<\beta<1, \gamma<0, \mu>0$, and $\theta<1$. This function is strictly concave.

Each household is endowed with one unit of labor services at each date and one unit of land, which provides one unit of land services at each date. Households are not able to sell their land. This assumption is nonbinding and is made to simplify the exposition.

\section{B. Industrial Sector}

In the industrial sector, there are three technologies that can be used to produce each differentiated good. Each of these technologies displays constant returns to scale and has labor services as its only input. Technology $k \in\{0,1,2\}$ for producing the $i^{\text {th }}$ industrial good is defined by the constraint

$$
X(i, t) \leq \pi_{k} N(i, t),
$$

where $N(i, t)$ is the labor input, $X(i, t)$ is the output, and $\pi_{0}<\pi_{1}<\pi_{2}$.

No firm-specific investment is required for an individual or group of individuals to 
adopt any of these three technologies. The reason we abstract from these investments is that they are not needed to show that monopoly rights can lead to the nonadoption of the $\pi_{2}$ technology and to the inefficient operation of the $\pi_{1}$ technology.

\section{Farm Sector}

In the farm sector, there is a constant returns to scale technology for producing the agricultural good, $A$, which is described by the nested CES production function:

$$
A(t)=\left[\psi\left(\int_{0}^{1} X_{a}(i, t)^{\sigma} d i\right)^{\rho / \sigma}+(1-\psi)\left(N_{a}(t)^{\alpha} L_{a}(t)^{(1-\alpha)}\right)^{\rho}\right]^{1 / \rho}
$$

where $X_{a}(i, t)$ denotes the input of the $i^{t h}$ differentiated good, $N_{a}(t)$ the input of labor services, and $L_{a}(t)$ the input of land services. The parameters satisfy $0<\psi<1,0<\alpha<1$, $0<\rho<1$, and $\sigma<0$. Thus, the composite of intermediate goods produced in the industrial sector is a substitute for the composite labor-land input.

The assumption that $\sigma<0$ is made to ensure that the farm sector demand for each differentiated commodity is price inelastic. Similarly, our restriction on the preference parameter, $\gamma$, ensures that household demand for each differentiated product is price inelastic. These assumptions are made to simplify the analysis. Specifically, these assumptions imply that whenever monopoly characterizes an industry, the equilibrium price will be the highest price which deters entry. 


\section{Equilibrium Under the Monopoly Rights Arrangement}

Under the monopoly rights arrangement, there are strategic elements, and care must be taken in defining the equilibrium. These monopoly rights pertain to the industrial sector. The farm sector is perfectly competitive. The initial state of a differentiated good industry is the initial number of members of the coalition in that industry. All industries have the same state. A coalition has the right to dictate work practices and the wage rate for any firm that uses the $\pi_{1}$ technology and to limit its membership size. Through choice of work practices, the coalition determines the productivity $\pi_{x} \leq \pi_{1}$ of any firm that uses the $\pi_{1}$ technology.

These monopoly rights are protected as long as the coalition exists. A coalition will exist only if there is a surplus to its members. A group that wishes to enter an industry in which a coalition exists and that wishes to use the $\pi_{2}$ technology must make an investment of $N \phi$ units of labor services to overcome resistance associated with the protection of the monopoly rights. The cost to overcoming resistance, thus, increases in proportion to an economy's population size. This assumption implies that all results are invariant to population size. No such protection exists with respect to the $\pi_{0}$ technology. Any household can use the $\pi_{0}$ technology to produce a differentiated good at any time without having to overcome this resistance.

A free-rider problem is associated with overcoming resistance. Once one group makes the needed investment to overcome this resistance, in subsequent periods, any person or group can use the $\pi_{2}$ technology and need not make any investment to overcome resistance. 
In the period in which resistance is overcome, only the group that makes the investment can use the $\pi_{2}$ technology. This is to say that the group incurring the cost of overcoming resistance does not gain monopoly rights to the use of the $\pi_{2}$ technology.

The key strategic element is the entry-deterrent role of the coalition size. Coalition members are committed to work in the coalition's industry for the current period. For a sufficiently large coalition membership, we will show that it is not in the interest of a potential entrant to invest in overcoming the resistance so that it can use the $\pi_{2}$ technology.

In this section, we first describe the entry game of an industry. Next, we define a symmetric no-entry steady state. Then we develop a set of necessary and sufficient conditions for such a steady state. The algorithm we use to find the set of symmetric no-entry steady states is specified in the section on computing equilibria.

An equilibrium necessarily exists. An outline of an existence argument is as follows. Let $\zeta$ denote the fraction of coalitions that give up their monopoly rights. Given $\zeta$, there is an allocation that satisfies all the equilibrium conditions except for the condition that each coalition behaves optimally in deciding whether or not to give up its rights. Given $\zeta$, let $v(\zeta)$ denote the utility gained from keeping the monopoly rights. The function $v$ is continuous. If $v(\zeta)=0$ for some $\zeta$, an equilibrium exists, and that fraction of coalitions gives up their rights. If no such $\zeta$ exists, then $v$ is either positive for all $\zeta$ or negative for all $\zeta$. In the former case, there is a no-entry steady-state equilibrium. In the latter case, there is an equilibrium with entry in every industry. Thus, an equilibrium exists. If there is more than one equilibrium, the relevant equilibrium is probably the one with the least entry. We 
say this because coordinated action among the coalitions would be necessary for any of the other equilibria to be realized.

\section{A. The Game}

In each industry, the players are the coalition of factor suppliers and a potential entrant. These players take as given the demand for the output of their industry and the wage in the competitive farm sector. These elements can be taken as given because the industry is small in the economy, and the industry's behavior has no consequence for these elements.

In the first stage of this game, each member of the coalition noncooperatively decides whether to remain a member and commit itself to work in the industry for the current period or move to the farm sector. Leaving is voluntary, so stayers and goers must realize equal utility. For simplicity, we rule out side payments. This assumption implies that if there are both stayers and goers, everyone earns the farm sector wage. In the first stage of the game, the coalition also decides whether to admit new members and, if so, how many. The number

of coalition members in the $i^{\text {th }}$ industry in the period, $N_{x}(i)$, consists of those inherited from the past less those members who leave plus those who join. In equilibrium, for the coalition to exist, member compensation must be at least as large as the farm sector wage rate, $w_{a}$. The coalition members are a specialized group of factor suppliers because they are committed to work in the industry for the current period. This is the only reason why coalition members are a specialized factor of production in the model. An alternative structure 
might have this specialization be the result of technology-specific investments made in past periods.

In the second stage of the game, the potential entrant decides whether to overcome the resistance to the use of the $\pi_{2}$ technology. If the potential entrant does not make the investment needed to overcome the resistance, then in the third stage, the coalition picks the productivity $\pi_{x}(i) \leq \pi_{1}$ of firms that use the $\pi_{1}$ technology and the wage these firms must pay workers, $w_{x}\left(N_{x}(i)\right)$. If the potential entrant makes the investment required to overcome resistance, then in the third stage, the coalition picks $\pi_{x}(i)$ and $w_{x}\left(N_{x}(i)\right)$, and the entrant picks price $p_{e}$ noncooperatively. Conditional on entry, effectively, there is Bertrand price competition where the entrant has a marginal cost $w_{a} / \pi_{2}$ and no capacity constraint, and the coalition has zero marginal cost and the capacity constraint $\pi_{1} N_{x}(i)$.

The nature of the game, subsequent to the coalition's commitment to a size and the potential entrant's commitment to entry, is that the coalition will make it possible for competitive firms to employ its members to compete with the entrant through a choice of its members' productivity $\pi_{x}(i)$ and wage $w_{x}\left(N_{x}(i)\right)$. This is required for subgame perfection.

In addition to a subgame perfect equilibrium to the game in each industry, equilibrium requires utility maximization, profit maximization in the farm sector, and market clearing. Households and farmers are price takers. 


\section{B. A Set of Conditions for a No-Entry Equilibrium Outcome}

In this section, we develop a set of necessary and sufficient conditions for a symmetric equilibrium with no entry and with no changes in the membership sizes of the coalitions. The numeraire for our economy is the agricultural good. We let $p(i)$ denote the price of the $i^{\text {th }}$ differentiated good in units of the agricultural good. For a steady state with no entry, $p(i)=p$ for all $i$.

The elements that define a no-entry steady state are the vector of prices, $\left(p, w_{a}, w_{x}, r\right)$, where $r$ is the rental price of a unit of land; the measure of farmworker households, $N_{a}$; the measure of industrial worker households, $N_{x}$; consumption allocations, $\left(a_{h}, x_{h}\right)$ for $h \in\{a, x\}$; farm sector allocations, $\left(A, X_{a}, N_{a}, L_{a}\right)$; and representative industry allocations, $\left(X, N_{x}\right)$ and productivity, $\pi_{x}$.

\section{Farm Sector Equilibrium Conditions}

Agricultural firms act competitively, taking prices as given. Since the production technology is subject to constant returns to scale, we aggregate up to a stand-in firm. The maximization problem of the stand-in agricultural firm is

$$
\max _{X_{a}(\cdot), N_{a}, L_{a}}\left\{A-\int_{0}^{1} p(i) X_{a}(i) d i-w_{a} N_{a}-r L_{a}\right\}
$$

subject to (2).

If $p(i)=p$ for all $i \in[0,1]$, profit maximization implies equal-size purchases of each intermediate good by the farm sector. We use $F\left(X_{a}, N_{a}, L_{a}\right)$ to denote farm output when 
$X_{a}(i)=X_{a}$ for all $i \in[0,1]$; that is,

$$
A=F\left(X_{a}, N_{a}, L_{a}\right) \equiv\left[\psi X_{a}^{\rho}+(1-\psi)\left(N_{a}^{\alpha} L_{\alpha}^{1-\alpha}\right)^{\rho}\right]^{1 / \rho}
$$

Maximization of profits with respect to $X_{a}, N_{a}$, and $L_{a}$ yields the following set of three necessary conditions for equilibrium:

$$
\begin{gathered}
p=F_{X}\left(X_{a}, N_{a}, L_{a}\right) \\
w_{a}=F_{N}\left(X_{a}, N_{a}, L_{a}\right) \\
r=F_{L}\left(X_{a}, N_{a}, L_{a}\right) .
\end{gathered}
$$

\section{Household Sector Equilibrium Conditions}

We categorize households by their worker type $h \in\{a, x\}$, where $a$ denotes a farmworker household and $x$ denotes an industrial worker household. For a no-entry steady-state equilibrium, these are the only worker types. The distinction of households by worker type is necessary because these groups have different incomes and, therefore, different demand functions. The incomes of workers in either sector consist of their wages, $w_{h}$, and land-rental incomes, $r$.

A household of type $h$ chooses an infinite sequence of differentiated goods and the agricultural good to maximize the discounted stream of utility subject to the intertemporal budget constraint. The necessary no-entry steady-state conditions for utility maximization 
are

$$
p=\frac{x_{h}^{\gamma-1} a_{h}^{1-\gamma}}{\mu}
$$

and

$$
a_{h}+p x_{h}=w_{h}+r
$$

for all $h \in\{a, x\}$. In equations (8) and (9), we exploit the steady-state condition that $p(i)=$ $p$ and $x_{h}(i)=x_{h}$ for all $i \in[0,1]$. In equation (9), we use the no-entry steady-state condition that income of the type $h$ household is the same every period.

\section{E. Market-Clearing Conditions}

The economy has four types of markets: the labor market, the land market, the agricultural good market, and the differentiated goods market. The market-clearing conditions are

$$
\begin{gathered}
\sum_{h} N_{h} x_{h}+X_{a}=X \\
\sum_{h} N_{h} a_{h}=A \\
N_{a}+N_{x}=N \\
L_{a}=N .
\end{gathered}
$$




\section{F. Game Equilibrium Conditions}

For the economy with monopoly rights, the coalition of factor suppliers to firms in the $i^{\text {th }}$ industry that use technology $\pi_{1}$ has the right to specify the price of the coalition members' services, dictate work practices, and control membership in the group. Thus, firms in the $i^{\text {th }}$ industry that use the $\pi_{1}$ technology produce

$$
X(i)=\pi_{x}(i) n_{x}(i),
$$

where $\pi_{x}(i) \leq \pi_{1}$ is the productivity parameter that results from the work practices chosen by the coalition with the monopoly rights and $n_{x}(i)$ is the number of coalition members employed in the $i^{\text {th }}$ industry. There is free entry of such firms.

The objective of each coalition of specialized factor suppliers is to maximize income per member through a choice of work practices $\pi_{x}(i)$ and the wage rate $w_{x}(i)$. All coalition members are employed if

$$
p(i) \pi_{x}(i) \geq w_{x}(i) .
$$

This being the case, a necessary condition for maximizing income per member is

$$
p(i) \pi_{x}(i)=w_{x}(i) .
$$

As coalition members do not value leisure and $\pi_{x}(i)$ is a choice variable, without loss of generality, we can and will assume that all coalition members are employed. For this reason, $w_{x}(i)$ is the compensation per coalition member as well as the wage rate, and $N_{x}(i)$ is the 
coalition size as well as the coalition employment.

To determine the necessary conditions for a subgame perfect equilibrium outcome with no entry, we use backward induction. Before proceeding, it is necessary to determine total demand for the $i^{\text {th }}$ differentiated good. Total demand for the $i^{\text {th }}$ differentiated good is the sum of the farm sector and household sector demands. The farm sector's demand for the $i^{\text {th }}$ differentiated good is obtained as follows. Set $p(i)$ equal to the derivative of the farm sector's production function with respect to $X_{a}(i)$ with $X_{a}\left(i^{\prime}\right)$ equal to $X_{a}$ for all $i^{\prime} \neq i$. Solve this equation for $X_{a}(i)$. The solution is the farm sector's demand. A type $h$ household's demand for the $i^{\text {th }}$ differentiated good is obtained as follows. In (8), set $p$ equal to $p(i), x_{h}$ equal to $x_{h}(i)$, and solve this equation for $x_{h}(i)$. The solution is the type $h$ household's demand. To obtain total demand for the $i^{\text {th }}$ differentiated good, sum demands over all households and the farm sector.

Stage 3 At this stage, $N_{x}(i)$ has been determined and entry either has or has not occurred. When there has not been entry, industry output is

$$
X(i)=\pi_{x}(i) N_{x}(i) .
$$

Because demand for each differentiated good is price inelastic, the coalition of factor suppliers to the $i^{\text {th }}$ industry maximizes its total member compensation by setting its work practices and wage rate so that the price of the $i^{t h}$ good is the one at which a firm using the $\pi_{0}$ 
technology breaks even. This price is

$$
p(i)=w_{a} / \pi_{0}
$$

In the relevant case where the coalition's size is sufficiently large to produce the total quantity demanded at this price, income per coalition member, $w_{x}\left(N_{x}(i)\right)$, is

$$
w_{x}\left(N_{x}(i)\right)=\frac{D\left(w_{a} / \pi_{0}\right)}{N_{x}(i)} \frac{w_{a}}{\pi_{0}},
$$

where $D$ denotes total demand for the $i^{\text {th }}$ differentiated good. Work practices of the coalition are

$$
\pi_{x}(i)=\frac{D\left(w_{a} / \pi_{0}\right)}{N_{x}(i)}
$$

Membership size is sufficiently large to produce the total quantity demanded if $\pi_{1} N_{x}(i) \geq$ $D\left(w_{a} / \pi_{0}\right)$.

If there has been entry, the entrant has marginal cost $w_{a} / \pi_{2}$ and no capacity constraint, while the coalition has zero marginal cost up to the capacity constraint, $\pi_{1} N_{x}(i)$. The coalition has zero marginal cost because having set its membership size at the beginning of the period, its members are stuck in that industry for the period. In the relevant cases where the output of the entrant is positive, the entrant's choice of price is

$$
p\left(N_{x}(i)\right)=\arg \max _{p}\left\{\left(p-\frac{w_{a}}{\pi_{2}}\right)\left(D(p)-\pi_{1} N_{x}(i)\right)\right\} .
$$


The first term inside the brackets is the difference between price and marginal cost per unit of output. The second term is the sales accruing to the entrant. Its sales are the total quantity demanded at the chosen price less output from firms that employ coalition members. The reason that firms that hire coalition members supply $\pi_{1} N_{x}(i)$ units of the $i^{t h}$ good is that given a price of the entrant, the coalition maximizes per member income by choosing $\pi_{x}(i)=\pi_{1}$.

Stage 2 At this stage, $N_{x}(i)$ has been determined. Given this membership size, the potential entrant correctly foresees that if it enters, firms employing coalition members will produce $\pi_{1} N_{x}(i)$ units of output. Consequently, entry is deterred if

$$
\max _{p}\left\{\left(p-\frac{w_{a}}{\pi_{2}}\right)\left(D(p)-\pi_{1} N_{x}(i)\right)\right\} \leq w_{a} N \phi
$$

Entrant's profits are decreasing in $N_{x}(i)$. Consequently, there is a smallest $N_{x}(i)$ which deters entry. We use $N_{x}$ to denote this coalition size.

Stage 1 At this stage, the coalition members from the previous period decide whether to remain in the coalition or move to the farm sector. If the wage rate that each coalition member can earn by maintaining his or her membership is greater than the farm wage rate, the coalition will exist in the period. If the size of the previous period's coalition is the smallest size which deters entry, $N_{x}$, and member compensation for this membership size exceeds the farm wage rate, then the coalition maintains its size in the current period and deters entry. However, if member compensation is less than the wage rate in the farm sector 
for this initial membership size, then the coalition ceases to exist and entry is not deterred. This analysis of the equilibrium of the game leads to the following set of necessary conditions for a no-entry steady state: From Stage 2, there is the minimal deterrent-entry condition,

$$
\max _{p}\left\{\left(p-\frac{w_{a}}{\pi_{2}}\right)\left(D(p)-\pi_{1} N_{x}\right)\right\}=w_{a} N \phi
$$

From Stage 3, there are the income per coalition member maximizing conditions,

$$
\begin{gathered}
p=w_{a} / \pi_{0}, \\
w_{x}=\frac{D\left(w_{a} / \pi_{0}\right)}{N_{x}} \frac{w_{a}}{\pi_{0}}, \\
\pi_{x}=\frac{D\left(w_{a} / \pi_{0}\right)}{N_{x}} .
\end{gathered}
$$

Finally, from Stage 1, there is the entry-deterrent condition,

$$
w_{x} \geq w_{a} .
$$

A no-entry steady-state equilibrium must satisfy equations (4)-(17) as well as condition (18).

\section{Computing the Equilibria}

Next, we seek to examine to what extent the elimination of such monopoly rights could conceivably increase a country's per capita output. For this purpose, we describe the steps used to compute the equilibrium in an economy in which such rights are protected and 
an economy in which such rights do not exist. We have not yet defined an equilibrium for the economy without monopoly rights. This definition is the standard Theory of Value definition of a competitive equilibrium. The existence and uniqueness of a competitive equilibrium can be shown as follows.

Preferences are strictly convex, so the model has a stand-in household for which utility is maximized by any competitive equilibrium allocation given local nonsatiation. The social planner's problem is strictly concave and so has at most one solution. This establishes that there is at most one equilibrium. We now outline how to establish that a solution exists to the social planner's problem and that the solution can be supported as a competitive equilibrium. There are no dynamic elements, so the planning problem is a sequence of static problems. Any allocation for which the $x(i)$ differ can be strictly dominated by one for which they are equal for all $i$. This permits attention to be restricted to allocations for which $x(i)=$ $x$ for all $i$, making the planning problem finite dimensional. Since the value of the continuous objective function goes to minus infinity as $x$ or $a$ goes to 0 , these variables can be restricted to be greater than or equal to some sufficiently small but strictly positive $\varepsilon$. With these restrictions, the constraint set is a closed and bounded subset of a finite dimensional space and, therefore, compact. Given the continuity of the objective function, a maximum exists. This Pareto optimal allocation can be supported as a quasi-competitive equilibrium since preferences are convex and continuous, the aggregate technology set is convex, the commodity space is finite dimensional, and the representative household is not satiated. For this problem, the prices of the inputs must be positive since their marginal products 
are positive and marginal utilities are strictly positive. Thus, a less costly point in the consumption set exists. This is sufficient to ensure that a quasi-competitive equilibrium is a competitive equilibrium.

The set of necessary and sufficient conditions that we use to find the competitive equilibrium are as follows. The set includes the farm sector equilibrium conditions, the household sector equilibrium conditions, and the market-clearing conditions for the monopoly rights equilibrium: that is, equations (4)-(13). Since the $\pi_{2}$ technologies are the ones operated in the differentiated good industries and workers are indifferent between working in the industrial and the agricultural sector, conditions for equilibrium in the industrial sector are

$$
\begin{gathered}
p=w_{x} / \pi_{2} \\
X=\pi_{2} N_{x} \\
w_{x}=w_{a} .
\end{gathered}
$$

Conditions (4)-(13) and conditions (19)-(21) are necessary and sufficient conditions for a competitive equilibrium in the economy.

Important issues are existence and uniqueness of no-entry steady-state equilibrium under the monopoly rights arrangement. Our computational procedure finds all such equilibria, thereby resolving the existence and uniqueness questions for the model economy being studied. This is possible because finding an equilibrium reduces to finding a fixed point of a continuous function of a single unknown. 


\section{A. With Monopoly Rights}

As long as there is no adoption of the $\pi_{2}$ technology, the equilibrium outcomes are the same in all periods. Our candidate for steady-state equilibrium allocations and prices is computed as follows for the economy in which the coalition of factor suppliers set work practices, the price of their services, and their membership size. We search over $N_{a}$. Given a value of this variable, we find all the other variables from necessary conditions as follows:

STEP 1: Use the farm sector equilibrium conditions, (4)-(7), along with equilibrium conditions $L_{a}=N$ and $p=w_{a} / \pi_{0}$, to determine $\left(A, X_{a}, L_{a}\right)$ and prices $\left(r, w_{a}, p\right)$.

STEP 2: From the type a household's maximization problem, determine the implied $\left(a_{a}, x_{a}\right)$ given the prices determined in the previous step.

STEP 3: Determine $N_{x}$ from the labor market-clearing condition given $N_{a}$.

STEP 4: Determine $a_{x}$ using the market-clearing condition for $A$ and elements determined in earlier steps.

STEP 5: Use the type $x$ household's maximization problem along with $\left(r, p, a_{x}\right)$ to determine $x_{x}$ and $w_{x}$. 
STEP 6: Determine $X$ from the market-clearing conditions for the differentiated industrial goods.

STEP 7: Compute $\pi_{x}=X / N_{x}$.

The nature of the algorithm is to search over $N_{a}$ until we find the one (ones) for which the entry-deterrent condition is binding. The computational steps above define all the other variables as a function of $N_{a}$, so we are dealing with a one-dimensional search. In all the numerical examples we consider, we find that profits of the potential entrant increase monotonically with respect to the guessed value of $N_{a}$, and there is at most one solution. A solution is an equilibrium outcome with no adoption if, in addition, $w_{x} \geq w_{a}$. Otherwise, coalitions could not retain members.

\section{B. With Free Enterprise}

The algorithm for computing the unique competitive equilibrium searches over $N_{a}$. Given a value of this variable, we find all the other variables from necessary conditions as follows:

STEP 1: Same as Step 1 above except use $p=w_{a} / \pi_{2}$.

STEP 2: Use the labor market-clearing condition to calculate $N_{x}$. 
STEP 3: Use the previously computed prices, condition $w_{a}=w_{x}$, and household-type utilitymaximization conditions to calculate the consumption pairs $\left(a_{h}, x_{h}\right)$ for $h \in\{a, x\}$.

STEP 4: Calculate $X=\pi_{2} N_{x}$.

The unique competitive equilibrium is found when the market-clearing condition

$$
N_{a} x_{a}+N_{x} x_{x}+X_{a}=X
$$

is satisfied.

\section{Some Quantitative Findings}

In this section, we explore how much larger aggregate output would be if a country eliminated the protected monopoly rights tied to current work practices. We have constructed a parametric class of tractable model economies in which this policy experiment can be carried out. We now restrict this parametric class of economies to be consistent with a number of observations. We then use the resulting model economy to estimate the consequence for output of eliminating these monopoly rights.

In restricting our model economy, we must specify the empirical counterparts of the sectors that produce the $A$ and $X$ goods. The defining feature of the $A$ sector in our model is that there are no protected monopoly rights tied to the currently used technology for producing this good. In poor countries, the largest part of this sector's product consists of agricultural goods. However, it also includes a number of services that are produced and 
consumed in the household sector of poor countries. This production is not part of measured income and product. In rich countries, much of the production of these same services occurs in the market sector and, therefore, is part of the measured product. Examples of such services include those produced by hair salons, car repair shops, dry cleaners, and restaurants. These considerations lead us to include services of this type in the $A$ sector. In the case of the poor country, these services must be imputed. Consequently, the empirical counterpart of value added in sector $A$ for a poor country is larger than reported value added of the agriculture sector. In a poor country, such as India, the value added in agriculture is about one-third of the total market product. With the addition of imputed home production, the value added share of the total product of the $A$ sector is surely closer to one-half than onethird in such countries. In rich countries the $A$ sector is much larger than the agricultural sector as well. Indeed, the share of the final product that originates in sector $A$ is as large, if not larger, in rich countries than it is in poor countries, given the importance of services in rich countries.

We must also specify the empirical counterpart of a period in the model. A model period represents the amount of time before a group overcoming resistance to the use of the $\pi_{2}$ technology faces competition from firms using that technology. If the time before entry by followers is long, the value of the flow of profits for a group that overcomes resistance is large. The empirical counterpart of this profit period is not the time between innovation and entry by imitators in industries in the rich countries. It is not because innovation and imitation in the rich countries involve the application of newly discovered ideas. For poor 
countries, what is relevant is the time required to adopt proven technologies. For this reason, we see two years as an upper bound for the length of the model period.

Another issue involves the income side. There is no capital in our model economy. This being the case, for the empirical counterpart of the model, we treat depreciation of tractors and other capital goods as intermediate goods.

The particular representative economy in this set has the parameter values that are reported in Table 1 . There are 12 parameters, which may seem like a large number. However, the parameters $\theta, \beta$ and $\sigma$ do not enter into the steady state calculation. The values of $\theta$ and $\beta$ are relevant to the analysis of the next section. The value of $\beta$ is chosen to be consistent with an annual real interest rate equal to 4.5 percent. The absolute values of the industrial sector technology parameters, $\pi_{0}, \pi_{1}$, and $\pi_{2}$ likewise do not matter for the results. For this reason, the value of $\pi_{0}$ is set to 1 . Consequently, there are only 8 parameters whose values matter.

The values for $\pi_{1}$, and $\pi_{2}$ are selected to be consistent with what we think are reasonable differences between potential productivities of successful technologies. It is not uncommon for the next technological innovation to be between 2 and 3 times more productive than the current technology when these technologies are used efficiently. This leads us to select $\pi_{1}=3.0$ and $\pi_{2}=9.0$.

This leaves 6 parameters. We select these parameters so that the following equilibrium outcomes hold. The fraction of employment in the model's farm sector is 0.60 with monopoly rights and 0.14 in the free enterprise country. Land rental income relative to the sum of land 
rental and farm labor incomes is 0.14 in both countries. The intermediate goods' share of total farm product is 0.02 in the monopoly rights country and 0.72 in the free enterprise country. Finally, the rents received by workers in the differentiated goods sectors are 60 percent of the farm wage. This implies $w_{x} / w_{a}=1.6$ in the monopoly rights country.

Before we can compare output levels for the two policy arrangements, aggregate output must be defined. The definition is an important issue because the price of the industrial good relative to the agricultural good differs between the two economies. In making this comparison, we follow the procedure underlying the construction of the purchasing-power party GDPs in the Summers and Heston Penn World Tables. (See Irving B. Kravis et. al 1982.)

Table 2 reports the equilibrium outcome for the monopoly-rights economy and for the free-enterprise economy for a parameterization of the model that roughly matches the observations listed above. The effect on output of eliminating monopoly rights is striking. Comparing per capita output between the two economies, we see that eliminating monopoly rights increases output by a factor of 2.72 . Since our $A$ sector includes home production of farm households, which is not part of measured GDP and which is much more important in poor countries, standard national accounting methods would result in a difference exceeding 3.

This increase in output is due solely to an increase in total factor productivity, since [there is no increase in the labor input and since we abstract from capital accumulation]. This difference in total factor productivity is as large as the difference that Robert E. Hall 
and Jones (1998) find between the United States and India. As Table 2 shows, an important reason for the lower total factor productivity in the monopoly rights arrangement economy is the inefficiency at which the inferior technology is operated; the coalition of factor suppliers operates the $\pi_{1}$ technology at approximately one-half its productive potential.

The result that the superior technology is not adopted in the monopoly rights economy, and instead the inferior technology is used inefficiently, is robust to alternative values of the preference and technology parameters. Only if $\pi_{2} / \pi_{1}$ is huge (greater than 7.0), will the equilibrium outcome be characterized by the $\pi_{2}$ technology being used, and being used efficiently with the monopoly rights arrangement.

Our result is quantitatively reasonable along two dimensions. First, as Table 2 reports, the price of the industrial good relative to the $A$ good is 4 times higher in the poor country with the monopoly rights arrangements than in the rich country with the free enterprise arrangement. This is roughly the factor difference in the price of investment to consumption goods across rich and poor countries in the Summers and Heston data. Second, the parameterization implies a total cost of overcoming resistance that is 43 percent of industry's annual value added. Given that attempts by textile mill owners in India to implement better work practices resulted in industry wide strikes up to 11 months in duration (Wolcott, 1994), the implied cost of overcoming resistance in the model seems well within reason. 


\section{Compensatory Schemes}

Next, we consider whether some group can benefit by buying off a coalition with the monopoly rights to the $\pi_{1}$ technology. Clearly, society as a whole can finance the needed payments through small lump-sum taxes on all the households that would benefit from the lower price. However, as a practical matter, such a buyoff is difficult, if not impossible, especially in less developed countries. One reason why it is so difficult is that individuals who belong to a group of suppliers with monopoly rights are more than likely better paid than the average citizen. In a democratic society, explicit transfers to members of a group with above-average income are politically unpopular. This difficulty aside, buyoffs have other problems. One is the time inconsistency problem of government policy. If the promised compensation is spread over a number of years, society has an incentive to default on its promise. Lump-sum payments up front do not avoid this problem. With lump-sum payments and normal preferences, those who receive the compensation will save most of it. But society can then tax this wealth by one mechanism or another. Another problem is that there may be no way to preclude a new group of suppliers to firms that use the $\pi_{2}$ technology from attaining monopoly power and increasing the price, thereby eliminating the benefits to the consumers. For these reasons, we restrict our attention to a buyoff by a small group.

\section{A. Buyoff by a Subset of the Coalition}

Next, we consider the $i^{\text {th }}$ industry. We hold output, prices, and coalition membership size of all other industries, $j \neq i$, at their values for the monopoly arrangement equilibrium 
with no entry. Without loss of generality, we take the potential adopting group to be the coalition itself. Since the group itself is adopting the $\pi_{2}$ technology, there is no cost to overcoming resistance. Further, there is no need to keep more workers in the industry than are needed to meet industry demand. Consequently, some of the coalition members can be released into the farm sector. We emphasize that redundant workers can work in the farm sector in the period of the buyoff since the buyoff occurs before coalition members commit to work in the industry. Finally, group income is shared equally among all members including those who work in the industry and those who work in the farm sector.

If the coalition were to adopt the $\pi_{2}$ technology, it would choose in the period of adoption the number of production workers, $N_{s}$, to maximize coalition-member income:

$$
\left[D^{-1}\left(\pi_{2} N_{s}\right) \pi_{2} N_{s}+w_{a}\left(N_{x}-N_{s}\right)\right] / N_{x},
$$

where $D^{-1}(\cdot)$ is the inverse demand for the $i^{\text {th }}$ differentiated good. The first term in equation (22) is the monopoly revenue. The second term is the income earned by those coalition members who work in the farm sector. This maximization is subject to the constraint that the price not exceed $w_{a} / \pi_{1}$. Since demand is price inelastic, the maximizing price is the highest one deterring entry, and the optimal number of production workers is that number which is needed to produce the quantity demanded at that price. Because the coalition has given up its rights over the $\pi_{1}$ technology, anyone in the economy can use the $\pi_{1}$ technology and hire workers at competitive wages. Consequently, the highest price the coalition can charge for the product without bringing on entry in the period is $w_{a} / \pi_{1}$ and 
not $w_{a} / \pi_{0}$. In future periods, all coalition members earn the farm wage rate since monopoly power associated with the $\pi_{2}$ technology is assumed to last one period.

The coalition will give up its monopoly rights to the $\pi_{1}$ technology if the discounted stream of utility of its members associated with giving up these rights is greater than the discounted stream of utility associated with maintaining the status quo. The discounted stream of utility depends on agents' desire for smooth consumption as well as the rate at which they discount the future. Consequently, a value of the curvature parameter, $\theta$, and a value of the subjective time discount factor, $\beta$, must be specified. For the subjective time discount factor, $\beta$, a value of 0.92 is consistent with a real rate of interest of 4.5 percent, given a model period length of two years. For the curvature parameter, $\theta$, a value of -1.0 is the value typically used in the $\mathrm{RBC}$ and finance literature.

For these preference parameter values and the technology parameter values listed in Table 1, adopting the superior technology is counter to the interest of the coalition. The higher per member income earned in the first period is not high enough to compensate for the lower wages earned in all subsequent periods. This result holds for all values of $\theta$ less than 0 (when holding $\beta$ fixed at 0.92 ), and all values of $\beta$ between 1.00 and 0.23 (when holding $\theta$ fixed at -1.0$)$.

\section{B. Transferable Monopoly Rights}

The above finding that it is not in the interest of the coalition with $\pi_{1}$ monopoly rights to adopt the $\pi_{2}$ technology depends on the assumption that the coalition does not 
receive monopoly rights to the $\pi_{2}$ technology. While we think such rights are typically nontransferable, sometimes they are. One notable example is the U.S. coal mining industry, where boring machines replaced picks and shovels in the middle of the twentieth century. We, therefore, consider the following case of transferable monopoly rights.

For this case, the coalition allows any firm to use the $\pi_{2}$ technology as long as that firm hires coalition members, pays wages set by the coalition, and abides by work practices set by the coalition. For the coalition to choose to transfer its monopoly rights, its members must be made better off in terms of expected discounted utility. Group members not employed in the industry move to the farm sector. There are no gains if all members stay in the industry because industry revenue, which goes to the coalition, would fall since the backup technology would be $\pi_{1}$ rather than $\pi_{0}$.

Those individuals who lose membership in the coalition will be unemployed and receive a lump-sum payment of $\tau_{l}$ in the current period. In all subsequent periods, they will earn the farm wage. We let $N_{s}$ denote the number of members who stay in the industry and $\tau_{s}$ denote the lump-sum payment per stayer made to finance the payments to the leavers. The wage of a stayer in all periods is

$$
w_{s}=\frac{w_{a}}{\pi_{1}} \frac{1}{N_{s}} D\left(w_{a} / \pi_{1}\right)
$$

In equation $(23), w_{a} / \pi_{1}$ is the price which maximizes compensation per worker and $D(\cdot)$ is industry demand. We assume that memberships are terminated by a lottery. In the period of adoption, labor income is $w_{s}-\tau_{s}$ for stayers and $\tau_{l}$ for leavers. In future periods, labor income 
is $w_{s}$ for stayers and $w_{a}$ for leavers. The probability of having one's membership continued is $N_{s} / N_{x}$, and the probability of having one's membership terminated is $\left(1-N_{s} / N_{x}\right)$.

A group will transfer its monopoly rights if members' expected utility associated with doing so is greater than the utility of maintaining the status quo. If we let $U$ denote utility as a function of labor income and hold the prices of all other products fixed at their equilibrium value, the condition for the adoption of the $\pi_{2}$ technology is

$$
\begin{aligned}
\max _{N_{s}, \tau_{s}, \tau_{l}} & \left\{\frac{N_{s}}{N_{x}}\left(U\left(w_{s}-\tau_{s}\right)+\frac{\beta}{1-\beta} U\left(w_{s}\right)\right)\right. \\
& \left.+\left(1-\frac{N_{s}}{N_{x}}\right)\left(U\left(\tau_{l}\right)+\frac{\beta}{1-\beta} U\left(w_{a}\right)\right)\right\}>\frac{1}{1-\beta} U\left(w_{x}\right) .
\end{aligned}
$$

This maximization is subject to the constraint that within the coalition, transfers sum to 0 ; that is,

$$
N_{s} \tau_{s}=\left(N_{x}-N_{s}\right) \tau_{l} .
$$

For the numerical example of the previous section with $\beta=0.92$ and $\theta=-1.0$, it is not in the interest of the coalition to transfer its monopoly rights to the $\pi_{2}$ technology. This result holds for all values of $\beta$ between 0 and 1 (when holding $\theta$ fixed at -1.0 ) and for all values of $\theta$ less than -0.40 (when holding $\beta$ fixed at 0.92 ). Enhancing monopoly rights to make them transferable does not result in the adoption of the better technology. For our numerical example, the problem for technology adoption is not that there are too few monopoly rights but that there are too many. 


\section{Conclusion}

Until now, support for the view that monopoly rights can lead to large inefficiencies and impede economic progress has been empirical in nature. Theory provided no economic mechanism by which monopoly could have large effects. In this paper, we provide a mechanism for monopoly rights to have large effects upon aggregate output. For the illustrative numerical example, total factor productivity is almost three times higher for the free enterprise arrangement than it is for the monopoly rights arrangement. This is a big difference.

With capital accumulation the difference in output would be magnified. We say this because the neoclassical growth model, the ratio of steady state per capita incomes in two countries is equal to the ratio of their TFPs raised to the power $1 /(1-\alpha)$, where $\alpha$ is the total reproducible capital share in the Cobb-Douglas production function. If $\alpha=2 / 3$, which is the total reproducible capital share suggested by the augmented neoclassical growth models of N. Gregory Mankiw et. al (1992), Stephen L. Parente and Prescott (1994), and V. V. Chari et. al (1997), the factor difference in steady state outputs is equal to the factor difference in the TFP cubed.

The ability of a group of factor suppliers to earn monopoly rents by blocking the adoption of a superior technology depends on the cost of overcoming resistance as well as how much better is that technology. This suggests why groups may work to increase the costs of entry through lobbying activities, as modeled by Thomas J. Holmes and Schmitz (1995).

A feature of the monopoly rights arrangement is the free-rider problem associated 
with overcoming resistance. For two main reasons, we do not think the solution is a policy of granting those groups that overcome the resistance monopoly rights to the use of the superior technology. First, the government must play a key role in providing the needed protection to those groups with vested interests in the currently operated technology. If the government were to grant monopoly rights to the use of the superior technology to those groups overcoming the resistance, the government would destroy the rents that it was protecting. Second, even if monopoly rights to the superior technology were granted to some group, under the monopoly rights arrangement, the owner's monopoly rents would be transient. Those groups supplying input to the better technology would over time gain monopoly rights and would capture the monopoly rents. Thus, the monopoly rents earned by those who enter with the superior technology would be short-lived, as they are in the model.

We conclude the solution is not to protect the monopoly rights of the specialized factor suppliers but rather to adopt the free enterprise arrangement. With this arrangement, groups have no incentive to block the use of better work practices, and as a result, production is efficient. 


\section{References}

Aghion, Philippe and Howitt, Peter. "A Model of Growth Through Creative Destruction." Econometrica, March 1992, 60(2), pp. 323-51.

Allen, Beth; Deneckere, Raymond; Faith, Tom and Kovenok, Dan. "Capacity Precommitment as a Barrier to Entry: A Bertrand-Edgeworth Approach.” Research Department Staff Report No. 187, Federal Reserve Bank of Minneapolis, February 1995.

Bergson, Abram. "On Monopoly Welfare Losses." American Economic Review, December 1973, 63(5), pp. 853-70.

Bhagwati, Jagdish N. "Directly Unproductive, Profit-Seeking (DUP) Activities." Journal of Political Economy, October 1982, 90(5), pp. 98-1002.

Chari, V. V.; Kehoe, Patrick J. and McGrattan, Ellen R. "The Poverty of Nations: A Quantitative Investigation." Research Department Staff Report No. 204, Federal Reserve Bank of Minneapolis, October 1997.

Clark, Gregory. "Why Isn't the Whole World Developed? Lessons From the Cotton Mills." Journal of Economic History, March 1987, 47(1), pp. 141-73.

Cowan, Laing Gray. Privatization in the Developing World. New York: Greenwood Press, 1990.

Cowling, Keith and Mueller, Dennis C. "The Social Costs of Monopoly Power." Economic Journal, December 1978, 88(352), pp. 727-48.

Dixit, Avinash. "A Model of Duopoly Suggesting a Theory of Entry Barriers." Bell Journal of Economics, Spring 1979, 10(1), pp. 20-32. 
."The Role of Investment in Entry-Deterrence." Economic Journal, March 1980, 90(357), pp. 95-106.

Dixit, Avinash K. and Stiglitz, Joseph E. "Monopolistic Competition and Optimum Product Diversity." American Economic Review, June 1977, 67(3), pp. 297-308.

Grossman, Gene M. and Helpman, Elhanan. Innovation and Growth in the Global Economy. Cambridge, Mass.: MIT Press, 1991.

Hall, Robert E. and Jones, Charles I. "Why Do Some Countries Produce So Much More Output per Worker than Others?" Manuscript, Stanford University, 1998.

Harberger, Arnold C. "Monopoly and Resource Allocation." American Economic Review, May 1954, 44(2), pp. 77-87.

Holmes, Thomas J. and Schmitz, James A., Jr. "Resistance to New Technology and Trade Between Areas." Federal Reserve Bank of Minneapolis Quarterly Review, Winter 1995, 19(1), pp. 2-17.

Karmerschen, David R. "Welfare Losses From Monopoly." Western Economic Journal, 1966, 4, pp. 221-36.

Kravis, Irving B., Heston, Alan and Summers, Robert. World Product and Income: International Comparisons of Real Gross Product. Baltimore: The John Hopkins University Press, 1982.

Krueger, Anne O. "The Political Economy of Rent-Seeking Society." American Economic Review, June 1974, 64(3), pp. 291-303.

Kydland, Finn E. Chapter 5 in Decentralized Macroeconomic Planning. Ph.D. thesis, 
Carnegie Mellon University, 1973.

. "A Dynamic Dominant Firm Model of Industry Structure." Scandinavian Journal of Economics, 1979, 81(3), pp. 355-66.

Laitner, John. "Monopoly and Long-Run Capital Accumulation." Bell Journal of Economics, Spring 1982, 13(1), pp. 143-57.

Lorch, Klaus. "The Private Transaction and Its Longer-Term Effects: A Case Study of the Textile Industry in Bangladesh.” Manuscript, Center for Business and Government, Kennedy School of Government, 1988.

Mankiw, N. Gregory; Romer, David and Weil, David N. "A Contribution to the Empirics of Economic Growth." Quarterly Journal of Economics, May 1992, 107(2), pp. 407-37.

Marsden, Keith and Belot, Therese. "Private Enterprise in Africa: Creating a Better Environment." World Bank Discussion Paper No. 17, Washington D.C.: World Bank, 1987.

Murphy, Kevin M.; Shleifer, Andrei and Vishny, Robert W. "Income Distribution, Market Size, and Industrialization." Quarterly Journal of Economics, August 1989a, 104(3), pp. 537-64.

. "Industrialization and the Big Push." Journal of Political Economy, October 1989b, 97(5), pp. 1003-126.

Parente, Stephen L. and Prescott, Edward C. "Barriers to Technology Adoption and Development." Journal of Political Economy, April 1994, 102(2), pp. 298-321.

Romer, Paul. "New Goods, Old Theory, and the Welfare Costs of Trade Restrictions." 
Journal of Development Economics, February 1994, 43(1), pp. 5-38.

Schmalensee, Richard. "Entry Deterrence in the Ready-to-Eat Breakfast Cereal Industry." Bell Journal of Economics, Autumn 1978, 9(2), pp. 305-27. . "Economies of Scale and Barriers to Entry." Journal of Political Economy, December 1981, 89(6), pp. 1228-38.

Smith, Adam. An Inquiry Into the Nature and Causes of the Wealth of Nations. Ed. Edwin Cannan. New York: The Modern Library, 1937.

Spence, Michael. "Product Selection, Fixed Costs, and Monopolistic Competition." Review of Economic Studies, June 1976, 43(2), pp. 217-35. . "Entry, Capacity, Investment and Oligopolistic Pricing." Bell Journal of Economics, Autumn 1977, 8(2), pp. 534-44.

Wolcott, Susan. "The Perils of Lifetime Employment Systems: Productivity Advance in the Indian and Japanese Textile Industries, 1920-1938." Journal of Economic History, June 1994, 54(2), pp. 307-24. 


\section{Notes}

*Parente: Department of Economics, University of Pennsylvania, 3718 Locust Walk, Philadelphia, PA 19104-6297; Prescott: Department of Economics, University of Minnesota, 1160 Management and Economics, 271 19th Avenue South, Minneapolis, MN 55455, and Research Department, Federal Reserve Bank of Minneapolis. We thank the National Science Foundation for financial support and seminar participants at the University of Victoria (New Zealand), the University of Victoria (Canada), the University of Rochester, the University of British Columbia, the University of Chicago, and the Federal Reserve Board of Governors. Individually, we would like to thank Stephen Burnell, V. V. Chari, Larry Christiano, Boyan Jovanovic, Ian King, José-Víctor Ríos-Rull, Jim Schmitz, Randy Wright, and an anonymous referee for their comments and Chris House for his research assistance. The views expressed herein are those of the authors and not necessarily those of the Federal Reserve Bank of Minneapolis or the Federal Reserve System.

${ }^{1}$ Harberger (1954) estimates this inefficiency loss to be only one-tenth of one percent of output. Subsequent researchers such as David R. Kamerschen (1966), Abram Bergson (1973), and Keith Cowling and Mueller (1978) basically use the Harberger triangle approach but define products more narrowly, assume greater cross elasticities of substitution, and find effects as large as 5 percent of output conceivable. 


\section{Table 1}

Parameter Values

\begin{tabular}{cccc}
\hline \hline Preference & Industrial Sector & \multicolumn{2}{c}{ Farm Sector } \\
Parameters & Technology Parameters & \multicolumn{2}{c}{ Parameters } \\
\hline$\gamma=-0.11$ & $\pi_{0}=1.00$ & $\alpha=$ & 0.86 \\
$\mu=1.10$ & $\pi_{1}=3.00$ & $\psi=$ & 0.23 \\
& $\pi_{2}=9.00$ & $\rho=$ & 0.71 \\
& $\phi=0.14$ & & \\
\hline \hline
\end{tabular}


Table 2

Computative Performances Under the Alternative Arrangements

\begin{tabular}{lcc}
\hline \hline & $\begin{array}{c}\text { Monopoly Rights } \\
\text { Arrangement }\end{array}$ & $\begin{array}{c}\text { Free Enterprise } \\
\text { Arrangement }\end{array}$ \\
\hline $\begin{array}{l}\text { Relative GDP } \\
(\text { PPP })\end{array}$ & 1.00 & 2.72 \\
Final Product Shares & & \\
$\quad$ Industrial Goods & 0.47 & 0.43 \\
Farm Goods & 0.53 & 0.57 \\
& & \\
Income Shares & & 0.02 \\
$\quad$ Land Rents & 0.07 & 0.84 \\
Industrial Wages & 0.48 & 0.14 \\
Farm Wages & 0.45 & \\
Value Added Shares & & 0.84 \\
$\quad$ Industrial Sector & & 0.16 \\
Farm Wages & 0.48 & \\
Relative Wages & 0.52 & \\
$w_{x} / w_{a}$ & & 0.15 \\
Industrial Sector Productivity & 1.60 & \\
$\pi_{x}$ & & 9.00 \\
Relative Prices & 1.60 & \\
$p_{x} / p_{a}$ & & \\
\hline \hline
\end{tabular}

